\title{
Localizando ciudades en circuitos globales ${ }^{\star *}$
}

\begin{abstract}
There have long been cross-border economic processes. In the last hundred years, the inter-state system came to provide the dominant organizational form cross-border flows, with national states as its key actors. This condition has changed dramatically over the last decade and more, as a result of privatization, deregulation, the opening up of national economies to foreign firms and the growing participation of national economic actors in global markets. In this context, we see a re-scaling of what are the strategic territories that articulate the new system. The organizational architecture for cross-border flows that results from these re-scaling and articulations increasingly diverges from that of the inter-state system. My central effort here is to contribute to empirical and theoretical specification of this organizational architecture. Among the features examined here are the combination of centralization and dispersal trends, the disproportionate concentration of value and transactions in the North Atlantic, the role of cities in an increasingly digitized global economy, especially as illustrated by the growth of finance and specialized services, and the impact of information technologies on urban economies.
\end{abstract}

Keywords: globalization, cities networks, global circuits.

\section{Resumen}

Por largo tiempo han existido procesos económicos transfronterizos. En los últimos cien años, el sistema inter-estados vino a proveer la forma organizativa dominante para los flujos transfronterizos, con los estados nacionales como actores clave. Esta condición ha cambiado dramáticamente desde la década de los ochenta, como resultado de la privatización, desregulación, apertura de las economías nacionales a empresas extranjeras y la creciente participación de actores económicos nacionales en mercados globales. En este contexto, observamos un reescalamiento de los territorios estratégicos que articulan el nuevo sistema. La arquitectura organizativa para los flujos transfronterizos, resultante de estos reescalamientos y articulaciones, diverge cada vez más de la del sistema inter-estados. Mi esfuerzo central aquí es contribuir a la especificación teórica y empírica de esta arquitectura organizacional. Entre los rasgos aquí examinados están la combinación de las tendencias a la centralización y a la dispersión; la desproporcionada concentración de valor y transacciones en el Atlántico Norte; el rol de las ciudades en una economía global crecientemente digitalizada, como lo ilustra especialmente el crecimiento de las finanzas y de los servicios especializados; y el impacto de las tecnologías de la información en las economías urbanas.

Palabras clave: globalización, redes de ciudades, circuitos globales. 


\section{Introducción}

os procesos económicos transfronterizos no son nada nuevo. Los flujos de capital, de trabajo, de bienes, de materias primas, de viajeros han existido a través de los siglos. Asimismo, ha habido enormes fluctuaciones en el grado de apertura o cierre de los cuadros organizacionales dentro de las cuales se han dado estos flujos. Durante los últimos cien años, es el sistema inter-estatal el cual ha provisto el marco organizativo dominante para los flujos transfronterizos, con los estados nacionales como actores clave. Es esta condición la que ha cambiado dramáticamente desde la década de los ' 80 , como resultado de la privatización, desregulación, apertura de las economías nacionales a empresas extranjeras y la creciente participación de actores económicos nacionales en mercados globales.

En este contexto, observamos un reescalamiento de los territorios estratégicos que articulan el nuevo sistema. Con el desmantelamiento parcial o al menos el debilitamiento de lo nacional como unidad espacial, sobrevienen condiciones para el ascenso de otras unidades espaciales y escalas. Entre éstas se encuentra lo subnacional, particularmente ciudades y regiones; las regiones transfronterizas que incluyen dos o más entidades subnacionales; y las configuraciones supranacionales, como por ejemplo los mercados digitalizados y los bloques de libre comercio. Las dinámicas y los procesos que se territorializan, o que funcionan a estas diversas escalas, pueden en principio ser regionales, nacionales o globales. Hay una multiplicación de circuitos globales especializados para las actividades económicas que contribuyen a

Ralph Lewis Professor of Sociology, University of Chicago, y Centennial Visiting Professor, London School of Economics. E-mail: ssassen@uchicago.edu

Basado en la introducción de la autora al volumen editado por ella: Global Networks, Linked Cities, New York/London: Routledge, 2002.

Traducido por Diego Campos. constituir estas nuevas escalas y que simultáneamente se fortalecen por su emergencia.

La arquitectura organizacional para los flujos transfronterizos, que resulta de estos reescalamientos y articulaciones, diverge cada vez más de la del sistema inter-estatal. Los articuladores claves incluyen ahora no sólo a los estados nacionales, sino también a empresas y mercados cuyas operaciones globales vienen facilitadas por nuevas políticas y estándares transfronterizos producidos por estados, voluntariamente o no tanto. Entre los referentes empíricos para estos cuadros no estatales de articulación de la economía global se cuenta el creciente número de fusiones y adquisiciones transfronterizas de empresas, las amplias redes de filiales extranjeras, el número creciente de centros financieros nacionales que se integran al mercado financiero global.

Una consecuencia de éstos y de otros procesos es que un número creciente de ciudades juegan hoy un papel cada vez más importante en vincular directamente sus economías nacionales con circuitos globales. A medida que crecen las transacciones transfronterizas de todo tipo, también lo hacen las redes que unen configuraciones o grupos particulares de ciudades. Esto a su vez contribuye a la formación de nuevas geografías de centralidad que conectan las ciudades en una creciente variedad de redes transfronterizas, incluso atravesando viejas divisiones como la Norte-Sur.

Un rasgo clave de esta arquitectura organizacional es que ella contiene tanto las capacidades para una enorme dispersión y movilidad geográfica, así como también pronunciadas concentraciones territoriales de recursos, necesarias para la gestión y servicio de tal dispersión. La gestión y servicio de gran parte del sistema económico global tiene lugar en una red cada vez mayor de ciudades globales, o de ciudades que son más bien poseedoras de funciones de ciudades globales. La expansión de la gestión global y de actividades de servicio ubicadas en ciudades ha traí- 
do consigo un ascenso masivo y la expansión de áreas urbanas centrales, aún cuando grandes fragmentos de estas ciudades caen en una profunda pobreza y deterioro infraestructural. Mientras este rol de gestión global y de servicios involucra solamente ciertos componentes de las economías urbanas, ha contribuido al reposicionamiento de ciudades, tanto nacional como globalmente.

Más aún, al enfatizar el hecho de que los procesos globales están al menos parcialmente insertos en los territorios nacionales a través de su concentración en las ciudades, se introducen nuevas variables en las concepciones actuales acerca de la globalización económica y de la reducción del rol regulador del Estado. Es decir, mientras la "función global de la ciudad" está en parte ensamblada en esta red de lugares que son parte de territorios nacionales, la geografía para los nuevos procesos económicos globales mayores ignora hasta cierto punto la noción de que lo global y lo nacional son dos zonas mutuamente excluyentes como se asume en muchos análisis acerca del impacto de la economía global sobre la autoridad del Estado. Los estados nacionales han tenido que participar en la creación de los ambientes legales e institucionales que permitan contribuir a la formación de esta geografía transfronteriza de centralidades, en gran parte articulada en la red de ciudades globales.

Mi esfuerzo central aquí es contribuir a la especificación teórica y empírica de esta arquitectura organizacional ${ }^{1}$. Los factores

\footnotetext{
El libro a partir del cual se ha preparado este artículo se centra particularmente en cómo las ciudades ubicadas en un rango medio de la jerarquía global se articulan con los circuitos económicos transfronterizos, y en las capacidades de las nuevas tecnologías de la comunicación para reducir la desigualdad en este jerarquía. La posición de estas ciudades en el rango medio de la jerarquía global entrega, de alguna manera, una visión diferente acerca de la operación de las dinámicas claves involucradas, y llena un vacío en la discusión académica sobre este tema. Pero tal vez, y de manera más importante para los propósitos de investigación y teorización, nos permite captar una dinámica en formación, distinta al caso de las ciudades globales bien establecidas.
}

involucrados son muchos, incluyendo la política estatal, las capacidades producidas por las telecomunicaciones y las nuevas tecnologías en red, antiguas historias de ventajas económicas disfrutadas por algunas ciudades y la localización en jerarquías globales. Al examinar cómo las ciudades pasan a estar articuladas con los circuitos globales hay varias unidades de análisis posibles: arquitecturas actuales de conectividad técnica, globales y locales; empresas y filiales transoceánicas; transacciones transfronterizas tales como inversión y comercio; alianzas entre mercados financieros así como, más generalmente, las operaciones del mercado global de capitales; el crecimiento de mercados de trabajo transnacionales para profesionales y trabajadores especializados de servicios. Pero hay, en principio, muchas otras unidades de análisis que se podría haber considerado, tales como las redes de tráfico ilegal de personas, drogas y bienes robados; redes de inmigración; bienales de arte; el mercado del arte; patrones turísticos (no sólo turistas individuales), como las paradas de los grandes cruceros; redes de negocios de inmigrantes; redes de activistas, desde los ambientalistas y defensores de los derechos humanos hasta las redes de activistas de los pobres. Es imposible cubrir aquí un rango tan diverso de posibles unidades de análisis.

Entre los rasgos aquí examinados están la combinación de las tendencias a la centralización y a la dispersión; la desproporcionada concentración de valor y transacciones en el Atlántico Norte; el rol de las ciudades en una economía global crecientemente digitalizada, como lo ilustra especialmente el crecimiento de las finanzas y de los servicios especializados, y el impacto de las tecnologías de la información en las economías urbanas.

\section{Redes mundiales y centralización del control}

La geografía de la globalización contiene tanto una dinámica de dispersión como una 
de centralización. Las tendencias masivas hacia la dispersión espacial de actividades económicas a nivel metropolitano, nacional y global que asociamos con la globalización han contribuido a una demanda por nuevos tipos de centralización territorial de las funciones de gestión y control de alto nivel. No obstante la integración telemática de la producción geográficamente mundializada de manufacturas y de servicios, el trabajo de alta gestión tiende a beneficiarse de economías de aglomeración y, por ende, a localizarse en ciudades. Esto plantea una problemática entre la intersección de las economías de aglomeración justamente en aquellos sectores económicos altamente globalizados que tienden a producir productos parcialmente desmaterializados, tales como instrumentos financieros y servicios especializados. Un aspecto de esta intersección es el hecho que hemos encontrado que las redes de negocios son una variable crucial para extraer beneficios de las redes técnicas y se deben distinguir estas. Tales redes de negocios han sido decisivas desde mucho antes de que las tecnologías actuales fueran desarrolladas. Las redes de negocios en parte originan y asimismo se benefician de las economías de aglomeración y, por lo tanto, prosperan en ciudades aún hoy, cuando la comunicación simultánea global es posible. En mi análisis la variable clave que contribuye a la concentración espacial de funciones de alta gestión y por ende a una nueva modalidad de las economías de aglomeración es el grado hasta el cual esta dispersión geográfica ocurre bajo condiciones de concentración en el control y la apropiación de la renta.

Esta dinámica simultánea de dispersión y concentración geográfica es uno de los elementos centrales en la arquitectura organizacional del sistema económico global. Permítanme entregar algunos referentes empíricos y examinar luego algunas de las implicancias para la teorización de los impactos de la globalización y de las nuevas tecnologías en las ciudades.
El rápido crecimiento de filiales ilustra la dinámica simultánea de dispersión y concentración geográfica de las operaciones de una empresa. En 1999, las empresas tenían sobre medio millón de filiales fuera de sus países de origen, lo que ascendía a once trillones de dólares en ventas, una cifra muy significativa si consideramos que el comercio global contaba 8 trillones de dólares. Las empresas que tienen grandes cantidades de fábricas y puntos de venta de servicios (tales como los restaurantes MacDonalds, servicios de contabilidad, hoteles, etc.) geográficamente dispersos enfrentan masivamente nuevas necesidades de coordinación central y de servicios, especialmente cuando sus filiales involucran países extranjeros con sistemas legales y contables diferentes.

Otra instancia actual de esta negociación entre una dinámica global transfronteriza y ámbitos territoriales específicos es la de los mercados financieros globales. Los órdenes de magnitud en estas transacciones han aumentado drásticamente, como lo ilustran los 192 trillones de dólares en el comercio financiero de derivados en 2002, un componente mayor de la economía global. En comparación, el valor del libre comercio global de bienes y servicios, que también aumentó rápidamente, alcanza los 8 trillones de dólares. Las transacciones financieras están parcialmente incluidas en los sistemas electrónicos que hacen posible la transmisión mundial instantánea de dinero. Se ha prestado mucha atención a esta capacidad de transmisión instantánea de las nuevas tecnologías, lo que también ha conllevado a la noción de que neutralizan la geografía. Pero la otra mitad de la historia es el grado en el cual los mercados financieros globales están ubicados en una creciente red de ciudades, si bien permanecen desproporcionadamente concentrados en el Norte global. En realidad, los niveles de concentración en un número limitado de ciudades tanto a nivel global como nacional son inesperadamente elevados para un sector económico cada vez más globalizado y digitalizado. Al interior de los países, los centros financieros líderes concentran hoy en día una parte mayor 
de la actividad financiera nacional que hace diez años. Internacionalmente, las ciudades en el Norte global concentran sobre la mitad del mercado global de capitales. Este es un tema que discuto empíricamente en una sección posterior. Uno de los componentes del mercado global de capitales son los mercados de valores. A fines de los ochenta y comienzos de los noventa se observó la adición de mercados tales como Buenos Aires, Sao Paulo, Ciudad de México, Bangkok, Taipei, Moscú y un creciente número de empresas no nacionales listadas en la mayoría de estos mercados. El aumento en el número de mercados de valores ha contribuido a elevar el monto de capital que se puede movilizar a través de estos mercados; esto se refleja en el agudo crecimiento mundial de la capitalización del mercado de valores, que alcanzó sobre los 24 trillones de dólares en 2000, y más de 30 trillones de dólares en 2002. Este mercado de valores globalmente integrado, que posibilita la circulación de acciones listadas en los países integrados en la economía global, se inserta en una red de lugares estratégicos físicos.

Las modalidades específicas asumidas por la globalización a partir de los ochenta han creado requisitos organizacionales particulares. El desarrollo de mercados globales para servicios financieros y al productor, así como el crecimiento de la inversión como un importante tipo de transacción internacional, han contribuido a la expansión de las funciones de alta gestión y a la demanda de servicios especializados para las empresas ${ }^{2}$.

2 Una proposición central aquí, desarrollada en detalle en mi trabajo, es que no podemos tomar la existencia del sistema económico global como algo dado, sino que debemos examinar la producción de las condiciones necesarias para la globalización económica. Esto requiere examinar no sólo las capacidades de comunicación y el poder de las multinacionales, sino también la infraestructura de servicios y procesos de trabajo necesarios para la implementación de sistemas económicos, incluida la producción de aquellos insumos que constituyen la capacidad para el control global. Esta manera de conceptualizar la globalización económica transfiere el énfasis a la praxis del control global: el trabajo que
Con el término de servicios de alta gestión o funciones centrales no me refiero solamente al trabajo que se da al interior de las sedes de gestión (headquarters); aludo a todas las funciones financieras, legales, contables, de gestión, ejecutivas y de planificación de alto nivel, necesarias para dirigir una organización corporativa que opera en múltiples países. Estas funciones centrales están parcialmente radicadas en dichas sedes, pero más y más van siendo subcontratadas al sector de servicios altamente especializados para empresas, es decir, la red de empresas financieras, legales, contables y publicitarias que manejan las complejidades de operar en más de un sistema legal, contable, de cultura de propaganda nacional, etc., todo esto bajo condiciones de rápida innovación en todos estos sectores. Tales servicios han llegado a ser tan especializados y complejos que las sedes de gestión los compran de manera creciente a empresas especializadas, en lugar de producirlos en casa. Estas aglomeraciones de empresas que producen funciones centrales para la gestión y coordinación de sistemas económicos globales están desproporcionadamente concentradas en los países altamente desarrollados -particularmente, aunque no exclusivamente, en ciudades globales. Pero a medida que más y más países se integran a la economía global, observamos un crecimiento de estos sectores especializados en las ciudades globales o con funciones de ciudad global del Sur global. Tales concentraciones de funciones localizadas en una red de ciudades representan un factor estratégico en la organización de la economía global ${ }^{3}$.

conlleva producir y reproducir la organización y gestión de un sistema global de producción y un mercado global para las finanzas, ambos bajo condiciones de concentración en la apropiación de la renta. Recuperar el peso del lugar y de los procesos de trabajo implica que la globalización puede ser estudiada con gran detalle empírico.

3 Estamos viendo la formación de un complejo económico con una dinámica de valorización que tiene propiedades que lo distinguen claramente de otros complejos económicos cuyas dinámicas de valorización están articuladas con las funciones económicas públicas del Estado, siendo la manufactura fordista 
Analíticamente, es importante distinguir este componente específico para el manejo de la economía global de la economía corporativa de un país. Ese componente se inserta parcialmente en la estructura de gestión general de una economía nacional, pero también constituye un subsector especializado distinto. Este subsector puede ser concebido como parte de una red que conecta las ciudades globales a través del mundo por medio de filiales de empresas u otras oficinas representativas, servicios especializados y gestión de las transacciones en el mercado global de capitales y de inversión extranjera ${ }^{4}$. Esta distinción podría no importar para ciertas investigaciones; sí importa cuando el objetivo es entender la economía global.

Esta distinción también importa en cuanto a la regulación, especialmente de actividades transfronterizas. Si las funciones centrales estratégicas -aquellas producidas tanto en la sede de gestión como en el sector de servicios especializados- se localizan en una red de centros financieros, la regulación de estos sectores que representan una parte clave de la economía global implica un tipo de esfuerzo diferente de lo que sería el caso si la gestión a alto nivel estuviera geográficamente dispersa como las fábricas, outlets de servicios y filiales. Esta localización de funciones estratégicas en la red de ciudades también representa

el ejemplo más claro. Los mercados globales en finanzas y servicios avanzados operan parcialmente a través de un marco regulatorio que no está centrado en el Estado, sino en el mercado. Esto a su vez hace surgir el tema del control ligado a las actualmente inadecuadas capacidades para gobernar las transacciones en el espacio electrónico.

4 En este sentido, las ciudades globales deben distinguirse de las antiguas capitales de los imperios del pasado, dado que constituyen una función de redes transfronterizas y no simplemente la ciudad más poderosa del imperio. En mi conceptualización no existe entidad tal como una sola ciudad global que pudiera ser la capital única de un imperio; la categoría de ciudad global sólo tiene sentido como componente de una red global de lugares estratégicos. El subsector económico que contiene el control global y las funciones de comando se inserta parcialmente en esta red. una geografía estratégica para activismos políticos que buscan responsabilizar a las multinacionales, por ejemplo con respecto a estándares ambientales y de los lugares de trabajo.

Los mercados nacionales y globales, así como las multinacionales, requieren espacios centralizados para ejecutar el trabajo de globalización. Las finanzas y los servicios avanzados son industrias que producen lo que podríamos concebir como bienes organizacionales necesarios para la implementación y gestión de los sistemas económicos globales. Las ciudades son espacios privilegiados para la producción de estos servicios, particularmente los sectores de servicios internacionalizados más innovadores y especulativos. Más específicamente, las empresas líderes en las industrias típicamente llamadas de informática (incluso los servicios financieros) requieren una vasta infraestructura física que contenga nodos estratégicos con hiperconcentración de equipamiento; necesitamos distinguir entre la capacidad para la transmisión/comunicación global y las condiciones materiales que lo hacen posible. Finalmente, incluso las industrias más avanzadas tienen un proceso de producción que se encuentra determinado al menos en parte por el lugar, debido a la combinación de recursos que requiere aun cuando sus productos sean hipermóviles.

Teóricamente, esto se refiere a dos temas claves en los debates actuales y en el ámbito académico. Uno de ellos es la compleja articulación entre inmovilidad y movilidad del capital, y el otro es la posición de las ciudades en una economía global. En mi trabajo he buscado desarrollar la tesis que la movilidad de capital no puede ser reducida simplemente a aquello que se mueve, ni tampoco a las tecnologías que facilitan el movimiento. Más bien, los múltiples componentes que habitualmente consideramos como inmovilidad del capital son en realidad componentes de la movilidad de éste. Esta conceptualización nos permite reposicionar el rol de las ciudades en un mun- 
do crecientemente globalizado, por cuanto ellas contienen los recursos que les permiten a las empresas y los mercados tener operaciones globales 5 . La movilidad del capital, ya sea en forma de inversiones, comercio o filiales transoceánicas, necesita ser gestionada, asistida y coordinada. A menudo estos elementos se encuentran determinados por los lugares; sin embargo, son los componentes claves de la movilidad del capital. Finalmente, los Estados -órdenes institucionales determinados por los lugares- han jugado un rol a menudo crucial al producir ambientes regulatorios que facilitan la implementación de operaciones transfronterizas para sus empresas nacionales y extranjeras, así como para los inversionistas y los mercados (Sassen, 2001).

En resumen, centrar la atención en las ciudades hace posible reconocer el anclaje de múltiples dinámicas transfronterizas en una red de lugares, entre los cuales los más prominentes son las ciudades, particularmente las ciudades globales o aquellas con funciones de ciudad global. Esto a su vez asienta varios rasgos de la globalización con las condiciones e historias específicas de estas ciudades, en sus articulaciones variables con sus economías nacionales y con diversas economías mundiales a través del tiempo y el espacio (por ejemplo Abbott, 1996; Abu-Lughod, 1999; Allen et al., 1999; Cochrane et al., 1996; Lo \& Yeung; 1996; Santos et al., 1994). Esta óptica sobre la globalización contribuye a identificar una compleja arquitectura organizacional que traspasa las fronteras y que se encuentra tanto parcialmente desterritorializada como parcialmente concentrada espacialmente en las ciudades. Aún más, esto crea una enorme agenda de investigación en la que cada economía

5 Hay múltiples especificaciones para este argumento. Por ejemplo, y yendo en dirección opuesta, el desarrollo de instrumentos financieros que representan reposiciones inmobiliarias fijas en varios sistemas de circulación, incluidos los globales. Al hacerlo así, el significado de la fijación del capital se transforma parcialmente, y el capital fijo se transforma además en un sitio para la circulación. Para una elaboración más completa, ver Sassen (2001). particular, nacional o urbana, tiene sus modos de articulación con los circuitos globales en parte heredados. Una vez que tengamos más información acerca de esta varianza, podremos también ser capaces de establecer si la posición en la jerarquía global establece una diferencia, y las múltiples formas en que podría hacerlo.

\section{La geografía de los flujos transfronterizos de capital}

Este tipo de análisis de la globalización, que busca ubicar lugares estratégicos con hiperconcentración de recursos, así como redes transfronterizas que vinculan estos lugares con otros, nos ayuda a comprender hasta qué punto hay una geografía específica de la globalización, y el hecho de que no se trata de un evento planetario que abarque todo el mun$\mathrm{do}^{6}$. Es más bien una geografía cambiante, que se ha transformado durante los últimos siglos y las últimas décadas ${ }^{7}$, y que más recientemente ha llegado a incluir el espacio electrónico.

6 En contraste con la noción de globalización como una señal de transformación del mundo en un solo lugar, o que denota "la condición humana global", puede argumentarse que la globalización es también un proceso que produce diferenciación. Pero el alineamiento de las diferencias es de un tipo muy distinto al que se asocia con nociones tan diferenciadoras como el carácter, la cultura, la sociedad nacional. Por ejemplo, el mundo corporativo tiene hoy una geografía global, pero no se encuentra en todas partes del mundo; en realidad, tiene espacios altamente definidos y estructurados; en segundo lugar, se diferencia de manera creciente y muy marcada de los segmentos no corporativos en las economías de las ciudades globales o de los países donde opera. Hay una homogenización a lo largo de ciertas líneas que cruzan las fronteras nacionales, y hay una aguda diferenciación dentro de esas fronteras. La naturaleza jerárquica de las redes globales es todavía otra forma de diferenciación, aún dentro de la geografía un tanto homogeneizada de las centralidades, discutida anteriormente. Al homogeneizarse, las formas y los procesos globalizados tienden a tener una geografía distinta.

Necesitamos reconocer las condiciones históricas específicas para distintas concepciones de lo internacional o de lo global (King, 1995). Actualmente existe una tendencia a ver la internacionalización 
Un primer paso para captar esta geografía de la globalización es examinar algunos de los patrones de los flujos transfronterizos de capital. Éstos son a menudo utilizados como indicadores (parciales) de globalización económica. Los patrones empíricos de inversión extranjera directa y de finanzas globales muestran ambos una aguda concentración en ciertas áreas del mundo y una creciente incorporación de lugares particulares en el mundo menos desarrollado.

La evidencia deja en claro que el centro de gravedad está en la región del Atlántico Norte. El sistema económico nor-transatlántico (en particular los lazos entre la Unión Europea, Estados Unidos y Canadá) representa hoy en día la mayor concentración de procesos de globalización económica en el mundo. Esto es válido ya sea que se observen los flujos de inversión extranjera directa en general, las fusiones y adquisiciones transfronterizas en particular, los flujos financieros generales o las nuevas alianzas estratégicas entre centros financieros. Esta región da cuenta de dos tercios de la capitalización de valores del mercado mundial; del $60 \%$ del stock de inversión extranjera directa interna y $76 \%$ del stock externo; del $60 \%$ de las ventas mundiales y $80 \%$ de compras en fusiones y adquisiciones. Hay otras regiones importantes en la economía global que reciben flujos de capital: Japón, el sudeste asiático y Latinoamérica. Pero exceptuando algunos de los niveles absolutos de recursos de capital en Japón, estas regiones pierden relevancia ante el peso del sistema nor-transatlántico.

de la economía como un proceso que funciona en el centro, entramado hoy en el poder de las corporaciones multinacionales y de las empresas coloniales en el pasado. Podría observarse que las economías de muchos países periféricos están completamente internacionalizadas debido a los altos niveles de inversión extranjera en todos los sectores económicos y a la fuerte dependencia de los mercados mundiales de moneda "dura". Lo que los países altamente desarrollados tienen son concentraciones estratégicas de empresas y mercados que operan globalmente, la capacidad para la coordinación y control global y el poder. Esta es una forma muy distinta de lo internacional de la que encontramos en el Sur global.
Un segundo patrón importante es el crecimiento significativo en el nivel absoluto de flujos que se dirigen a otras partes del mundo, aun cuando no pueden compararse con la región del Atlántico Norte. Desagregando estos patrones, se deja en claro que se trata de un número selecto de lugares a los que en realidad se dirige el capital. Los flujos en Latinoamérica reflejan bien estos dos patrones: un aumento masivo en la inversión extranjera, pero concentrada principalmente en Brasil, México y Argentina.

Observamos la consolidación de un sistema económico transnacional que tiene su centro de gravedad en el sistema nor-atlántico, tanto en términos de la intensidad y valor de las transacciones, como en términos del emergente sistema de reglas y estándares. Este sistema se articula con una red cada vez más amplia de lugares para la inversión, el comercio y las transacciones financieras en el resto del mundo. Así como la globalización no induce la dispersión, es también evidente que la combinación de concentración y expansión de la red forman un sistema jerárquico fuerte.

El peso del sistema nor-atlántico en la economía global hace surgir un conjunto de preguntas. Una de ellas se refiere a sus características; el grado hasta el cual existe interdependencia y en ese sentido, los elementos de un sistema económico transfronterizo. El peso de estos lazos trans-atlánticos necesita ser considerado en relación con el peso de las zonas de influencia establecidas para cada uno de los poderes principales - particularmente el hemisferio occidental en el caso de Estados Unidos, y África, Europa Central y del Este para la Unión Europea.

En otra parte he argumentado que es a través de esta incorporación en una red global jerárquica que tiene su centro en el Atlántico Norte que se constituyen hoy las relaciones con sus zonas de influencia. Así, mientras Estados Unidos es todavía una fuerza dominante en Latinoamérica, varios países euro- 
peos se han transformado en inversionistas mayores en la región, en una escala que supera ampliamente tendencias pasadas. $Y$ mientras varios países de la Unión Europea han llegado a ser inversionistas líderes en Europa Central y del Este, las empresas de Estados Unidos están jugando un rol que no habían tenido nunca antes.

Lo que vemos hoy es una nueva red de transacciones económicas superpuestas sobre antiguos patrones geoeconómicos. Estos últimos persisten en diferentes grados, pero están crecientemente sumergidos bajo esta nueva red transfronteriza. Estas nuevas configuraciones son particularmente evidentes en la organización de las finanzas globales, y aunque en menor grado, en la inversión extranjera directa (IED), especialmente en las fusiones y adquisiciones transfronterizas ${ }^{8}$.

Las fusiones y adquisiciones transfronterizas dominan hoy los flujos globales de IED, y están fuertemente concentradas en países de la OECD, que dan cuenta de un 89\% de compras y $72 \%$ de ventas. Un número creciente de empresas opta por los fusiones como

8 Las condiciones sistémicas en la nueva geoeconomía constituyen un factor significativo en el tema de la regulación. Los órdenes de magnitud y la intensidad de las transacciones en el sistema noratlántico facilitan la formación de estándares, aún en el contexto de fuertes diferencias entre Estados Unidos y Europa continental en sus reglas legales, contables, anti-trust y otras. Es claro que aunque estas dos regiones tienen más en común entre ellas que con gran parte del resto del mundo, estas diferencias importan en lo que respecta a la creación de estándares transfronterizos. Sin embargo, los estándares y normas occidentales compartidas, en combinación con la enorme importancia económica, ha facilitado la circulación y la imposición de estándares y reglas de transacción estadounidenses y europeas, sobre las transacciones que involucran empresas de otras partes del mundo. Hay una suerte de globalización de los estándares occidentales. Mucho se ha dicho acerca de la dominación de los estándares y reglas de Estados Unidos, pero los estándares europeos son también evidentes, por ejemplo, en las nuevas reglas anti-trust que se están desarrollando en Europa del Este y central. modo de expansión o consolidación transoceánica. Por ejemplo, las adquisiciones representaron un $90 \%$ de la IED total en Estados Unidos en 1996. En 1998, las fusiones y adquisiciones en el Atlántico Norte alcanzaron 256,5 billones de dólares, desde 69,4 billones en 1995.

El índice promedio de transnacionalidad para la Unión Europea es de 56,7\%, comparado con un $38,5 \%$ para Estados Unidos (y $79,2 \%$ para Canadá). Este índice es un promedio basado en las proporciones que las ventas extranjeras, bienes y empleo representan en el total de cada empresa. El Índice ha crecido para las empresas transnacionales (TNCs) más grandes del mundo, desde que fuera usado por primera vez en 1990. La mayoría de las empresas transnacionales de Estados Unidos y la Unión Europea en esta lista de las 100 principales tienen niveles muy altos de activos extranjeros, como porcentajes de los activos totales: por ejemplo, $51 \%$ para IBM, 55\% para el Grupo Volkswagen, 91\% para Nestlé, 96\% para Asea Brown Boveri y así sucesivamente. Estados Unidos, el Reino Unido, Francia, Alemania y Japón dieron cuenta conjuntamente de tres cuartas partes de estas 100 firmas en 1997; grosso modo, esto ha sido así desde 1990 .

\section{Impactos de las nuevas tecnologías de la comunicación sobre las centralidades}

Históricamente las ciudades han contribuido con algo que podríamos denominar centralidad a las economías, los sistemas políticos y las sociedades nacionales. En términos de su función económica, las ciudades proporcionan economías de aglomeración, concentraciones masivas de información sobre desarrollos recientes, y un lugar para el mercado. ¿Cómo alteran las nuevas tecnologías de la comunicación el rol de las centralidades, y por lo tanto, el de las ciudades como entidades económicas? 
Como se ha indicado en secciones anteriores, la centralidad sigue siendo un rasgo clave de la economía global actual. Pero hoy en día ya no existe una relación simple y directa entre centralidad y entidades geográficas como el "centro" o distrito central de negocios (central business district -CBD). En el pasado, y en realidad hasta hace poco, el centro era sinónimo de centro histórico o CBD. Hoy, parcialmente como resultado de las nuevas tecnologías de la comunicación, los correlatos espaciales del centro pueden asumir formas geográficas variadas, que van desde CBD hasta las redes de transacciones, en gran medida electrónicas, que conectan a ciudades a través del mundo.

Simplificando, se podría identificar tres formas que hoy asumen las centralidades ${ }^{9}$.

Primero, mientras no hay ya una relación simple y directa entre centralidad y entidades geográficas como el "centro", como fue el caso en el pasado, este sigue siendo la modalidad clave de centralidad. Pero en los centros de negocios internacionales relevantes, el centro se encuentra profundamente reconfigurado por el cambio tecnológico y económico. Graham (2002) y García (2002) examinan la variedad de impactos de las nuevas tecnologías de la comunicación en esta reconfiguración.

En segundo lugar, el centro puede extenderse en un área metropolitana bajo la forma de una red de nodos de intensa actividad comercial, caso bien ilustrado por los recientes desarrollos en ciudades tan diversas como Buenos Aires (Cicolella \& Mignaqui, 2002) y París (Veltz, 1996; Landrieu et al., 1998). Uno podría preguntarse si una organización espacial caracterizada por nodos estratégicos densos, extendidos sobre una región más amplia, constituye o no una nueva forma de organización del territorio del "centro", más que -como

9 Hay un cuarto caso al cual me he referido en otra parte (Sassen, 2001), representado por nuevas formas de centralidad constituidas en los espacios generados electrónicamente. sucede en una visión más convencional- un ejemplo de suburbanización o dispersión geográfica. Por lo que respecta a estos nodos, si están articulados a través de ciber-rutas o carreteras digitales, representan un nuevo correlato geográfico del tipo más avanzado de "centro". Sin embargo, los lugares que caen fuera de esta nueva red de carreteras digitales son periferizados. Esta red regional de nodos representa, en mi análisis, una reconstitución del concepto de región. Lejos de neutralizar la geografía, es probable que la red regional sea articulada en formas convencionales de infraestructura de comunicaciones, particularmente ferrocarriles rápidos y carreteras que conectan con aeropuertos. Tal vez irónicamente, es probable que la infraestructura convencional maximice los beneficios económicos derivados de la telemática. Pienso que este es un punto importante que, de alguna manera, se ha perdido en las discusiones acerca de la neutralización de la geografía a través de la telemática.

En tercer lugar, estamos viendo la formación de un "centro" trans-territorial constituido a través de la telemática e intensas transacciones económicas. La más poderosa de estas nuevas geografías de centralidades son los niveles interurbanos que vinculan los mayores centros financieros y de negocios internacionales: Nueva York, Londres, Tokio, París, Francfort, Zurich, Amsterdam, Los Angeles, Sydney y Hong Kong, entre otros ${ }^{10}$. Pero esta geografía incluye ahora ciudades como Sao Paulo y Ciudad de México. La intensidad

10 En el caso de un paisaje complejo como el de Europa vemos en realidad geografías de centralidades, una global, otras continentales y regionales. Una jerarquía urbana central conecta las ciudades principales, muchas de las cuales a su vez juegan roles centrales en los sistemas globales más amplios de ciudades: París, Londres, Francfort, Ámsterdam, Zurich. Estas ciudades son también parte de una red más amplia de capitales europeas financieras, culturales y de servicio. Algunas de ellas con sólo una, otras con varias de estas funciones, articulan la región europea y están en parte menos orientadas a la economía global que París, Francfort o Londres. $Y$ luego hay varias geografías de marginalidad: 
de las transacciones entre estas ciudades, particularmente a través de los mercados financieros, comercio de servicios e inversión, ha aumentado rápidamente, y también lo han hecho los órdenes de magnitud involucrados. Finalmente, vemos emerger jerarquías regionales, como lo ilustran los corredores de crecimiento del sudeste asiático (Lo \& Yeung, 1996), el caso de Sao Paulo en el área de libre comercio del Mercosur (Schiffer, 2002) y la relación entre las entidades participantes en el corredor Irán-Dubai (Parsa \& Keivafin, 2002).

Además de su impacto en los correlatos espaciales de las centralidades, puede esperarse que las nuevas tecnologías de la comunicación tengan un impacto sobre la desigualdad entre las ciudades principales y las ciudades interiores. En gran parte de la literatura existe la expectativa de que estas tecnologías desconocerán las antiguas jerarquías y desigualdades espaciales a través de la universalización de la conectividad que representan. La evidencia disponible sugiere que este no es el caso. Ya sea la red de centros financieros y los patrones de inversión extranjera directa discutidos en este artículo, o los análisis más específicos acerca de la organización espacial de varias ciudades, las nuevas tecnologías de la comunicación no han reducido jerarquías ni desigualdades espaciales (Graham, 2002; Graham \& Marvin, 2001; Castells, 1996). Y esto es así aún frente al progreso y desarrollo de infraestructura en un número cada vez mayor de ciudades alrededor del mundo. Hay pocas dudas acerca de que la conexión a circuitos globales ha traído consigo un significativo nivel de desarrollo de

la división Oeste-Este y la división Norte-Sur a través de Europa, así como divisiones más nuevas. En Europa del Este, ciertas ciudades y regiones, principalmente Budapest, son bastante atractivas para propósitos de inversión, tanto europea como no europea, mientras otras se quedarán cada vez más atrás, especialmente Rumania, Yugoslavia y Albania. Vemos una diferenciación similar en el sur de Europa: Madrid, Barcelona y Milán están ganando en la nueva jerarquía europea; Nápoles, Roma y Marsella, no. extensas áreas centrales urbanas y de las redes metropolitanas de nodos de negocios y un considerable dinamismo económico. Pero la cuestión de la desigualdad no ha sido implicada.

Aún más, la pronunciada orientación hacia los mercados mundiales, evidente en muchas de estas ciudades, hace surgir preguntas acerca de la articulación de éstas con sus estados-nación, regiones y estructuras sociales y económicas mayores. Típicamente, las ciudades han estado profundamente insertas en las economías de su región, reflejando en realidad a menudo características de estas últimas; y aún lo hacen. Pero las ciudades que son lugares estratégicos en la economía global tienden, en parte, a desconectarse de su región. Esto entra en conflicto con una proposición clave en el pensamiento académico tradicional acerca de los sistemas urbanos; a saber, que estos sistemas promueven la integración territorial de las economías regionales y nacionales. Ha habido una marcada desigualdad en la concentración de recursos estratégicos y actividades entre cada una de estas ciudades y otras en los mismos países, aunque esto tiende a ser evidente sólo a niveles bastante desagregados. Por ejemplo, Ciudad de México concentra hoy una parte mayor de ciertos tipos de actividad económica y de producción de valor que lo que hacía en el pasado, pero para observar esto se requiere un set particularizado de análisis, como nos lo muestra Parnreiter (2002) ${ }^{11}$.

11 Esto es válido también en el mundo altamente desarrollado. Por ejemplo, la región de París representa más de un $40 \%$ de todos los servicios al productor en Francia, y sobre el $80 \%$ de los más avanzados. Se estima que Nueva York representa entre un cuarto y un quinto de toda la exportación de servicios al productor, aunque tiene sólo un 3\% de la población de Estados Unidos. Londres representa un $40 \%$ de todas las exportaciones de servicios al productor en el Reino Unido. Tendencias similares son también evidentes en Zurich, Francfort y Tokio, todas ubicadas en países mucho más pequeños. 


\section{Intersección entre intensidad de servicios y globalización}

Para entender la novedad del rol ampliamente extendido de un tipo particular de ciudad en la economía mundial desde comienzos de los '80, necesitamos centrarnos en la intersección de dos procesos mayores. El primero es el marcado incremento en la globalización de la actividad económica; esto ha elevado la escala y la complejidad de las transacciones, intensificando por ende el desarrollo de las funciones centrales multinacionales de nivel superior y el desarrollo de los servicios especializados. Es importante notar que aunque la globalización eleva la escala y la complejidad de estas operaciones, éstas son también evidentes a escalas geográficas menores y a niveles más bajos de complejidad que aquellos de las multinacionales, como es el caso de empresas que operan regionalmente. De esta manera, aunque las empresas regionales no necesitan negociar las complejidades de las fronteras internacionales y las regulaciones de diferentes países, aún enfrentan la red de operaciones regionalmente dispersa que requiere de control y servicios centralizados.

El segundo proceso que necesitamos considerar es el crecimiento en la intensidad de los servicios en la organización de todas las industrias. Esto ha contribuido a un masivo incremento en la demanda por servicios de parte de las empresas en todas las industrias, desde la minería y la manufactura hasta las finanzas y los servicios al consumidor ${ }^{12}$. Indus-

12 Podemos pensar en los servicios al productor, y más especialmente, en las finanzas y los servicios avanzados como las industrias que producen "bienes organizacionales" necesarios para la implementación y gestión de sistemas económicos globales (Sassen, 2001). Los servicios al productor son outputs intermedios, es decir, servicios comprados por las empresas. Ellos cubren asuntos financieros, legales y de gestión en general, innovación, desarrollo, diseño, administración, personal, tecnología de producción, mantención, transporte, comunicaciones, distribución mayorista, publicidad, servicios de aseo para empresas, seguridad y almacenamiento. trias con negocios mixtos y mercados orientados al consumidor; tales son los seguros, bancos, servicios financieros, propiedades, servicios legales, contabilidad y asociaciones profesionales (para una discusión más detallada ver, por ejemplo, Noyelle y Dutka, 1988; Daniels, 1991; Veltz, 1996). Las ciudades son lugares clave para la producción de servicios para las empresas. Debido a esto, el aumento en la intensidad de los servicios en la organización de todas las industrias ha tenido un efecto significativo de crecimiento en las ciudades, comenzando en los '80 y continuando hasta hoy. Es importante reconocer que este crecimiento en los servicios a las empresas es evidente en las ciudades a niveles diferentes dentro del sistema urbano de una nación. Algunas de estas ciudades abastecen mercados regionales o subnacionales; otras proveen mercados nacionales y otras, hasta mercados globales. En este contexto, la globalización se transforma en un asunto de escala y complejidad agregada.

El proceso clave desde la perspectiva de la economía urbana es la creciente demanda de servicios por parte de las empresas en todas las industrias, y el hecho de que las ciudades son los lugares preferentes de producción de tales servicios, ya sea en el ámbito global, nacional o regional. Como resultado, observamos en las ciudades la formación de un nuevo núcleo económico urbano de banca y actividades de servicio que viene a reemplazar el viejo núcleo típicamente orientado a la manufactura.

En el caso de ciudades que son centros de negocios internacionales mayores, la escala, el poder y los niveles de ganancia de este nuevo núcleo sugieren que estamos ante la formación de una nueva economía urbana. Esto es así por lo menos en dos aspectos. Primero, aún cuando estas ciudades han sido por largo tiempo centros de negocios y finanzas, desde fines de la década de los setenta ha habido cambios dramáticos en la estructura de los sectores de negocios y financieros, así como marcados incrementos en la magnitud general de estos sec- 
tores y en su peso en la economía urbana. Segundo, la emergencia de un nuevo complejo de finanzas y servicios, particularmente de finanzas internacionales, engendra lo que puede ser considerado un nuevo régimen económico; esto es, aunque este sector representa sólo una fracción de la economía de una ciudad, se impone a sí mismo en aquella economía mayor. Más particularmente, la posibilidad de obtener ganancias extraordinarias en las finanzas tiene el efecto de desvalorizar la manufactura, ya que esta última no puede generar los enormes beneficios típicos de muchas actividades financieras.

Esto no quiere decir que todo en la economía de estas ciudades haya cambiado. Por el contrario, éstas todavía muestran una gran continuidad y muchas similitudes con ciudades que no son nodos globales. Más bien, la implantación de procesos y mercados globales ha significado que el sector internacionalizado de la economía se ha expandido en forma pronunciada y ha impuesto una nueva dinámica de valorización -es decir, un nuevo conjunto de criterios para valorar o poner precio a diversas actividades económicas y productos. Esto ha tenido efectos devastadores en grandes sectores de la economía urbana. Los altos precios y niveles de ganancia en el sector internacionalizado y sus actividades subsidiarias, como restaurantes y hoteles de lujo, han hecho cada vez más difícil para otros sectores la competencia por espacio e inversiones. Muchos de estos otros sectores han experimentado una considerable desvalorización y/ o desplazamiento, como por ejemplo tiendas de barrios que son reemplazadas por boutiques y restaurantes de alto nivel, los cuales abastecen a las nuevas elites urbanas de altos ingresos.

Aunque en un orden de magnitud diferente, estas tendencias se hacen también evidentes -desde fines de los ochenta y comienzos de los noventa- en varias ciudades importantes del mundo en desarrollo, que se han integrado a diversos mercados mundiales: Sao Paulo, Buenos Aires, Bangkok, Taipei,
Shanghai, Manila, Beirut y Ciudad de México son sólo algunos ejemplos. También aquí el nuevo núcleo urbano fue alimentado por la desregulación de varios sectores económicos, el ascenso de las finanzas y servicios especializados y la integración en los mercados mundiales. La apertura de mercados de valores a los inversionistas extranjeros y la privatización de lo que alguna vez fueron empresas del sector público han sido escenarios institucionales cruciales para esta articulación. Dado el gran tamaño de algunas de estas ciudades, el impacto de este nuevo núcleo en la ciudad más vasta no es siempre tan evidente como en la parte central de Londres o Francfort, pero la transformación es aún así muy real.

Es importante reconocer que la manufactura permanece como un sector crucial en todas estas economías, aún cuando puede haber dejado de ser dominante en las ciudades más importantes. En realidad, varios autores han argumentado que el sector de servicios al productor no podría existir sin la manufactura (Cohen \& Zysman, 1987; Markusen \& Gwiasda, 1994; Mitchell, 1996). Una proposición clave para estos y otros autores es que los servicios al productor dependen de un sector manufacturero fuerte para crecer. Hay un amplio debate en torno a este asunto. Drennan et al. (1996) argumentan que finanzas fuertes y un sector de servicios al productor sí son posibles en las ciudades principales de Estados Unidos, a pesar del declive en su base industrial y de que estos sectores están integrados tan fuertemente en los mercados mundiales, que la articulación con la región se vuelve secundaria.

En una variante respecto de ambas posiciones, he argumentado que la manufactura ciertamente alimenta el desarrollo del sector de los servicios al productor, pero esto sucede ya sea que esté localizada en el área en cuestión o en algún otro lugar del país o en ultramar (Sassen, 2001). Aunque la manufactura -y la minería y la agricultura, por lo que a esto respecta- estimula el crecimiento en la 
demanda de servicios al productor, su localización actual es de importancia secundaria para el caso de empresas de servicio de nivel global; así, el que las plantas manufactureras estén ubicadas en ultramar o dentro de un país puede ser bastante irrelevante, siempre y cuando sea parte de una corporación multinacional con posibilidades de comprar los servicios de aquellas empresas de alto nivel. Segundo, la dispersión territorial de fábricas, especialmente si son internacionales, eleva en realidad la demanda de servicios del productor. Este es todavía otro significado o consecuencia de la globalización: el crecimiento de empresas de servicios al productor cuyas sedes de gestión están en Nueva York, Londres o París puede ser alimentado por una manufactura emplazada en cualquier lugar del mundo, siempre y cuando sea parte de una red corporativa multinacional. Tercero, una buena parte del sector de servicios al productor es potenciado por transacciones financieras y de negocios que no tienen nada que ver con la manufactura, como es el caso de muchos de los mercados financieros globales, o para los cuales ésta resulta incidental, como en gran parte de la actividad de fusiones y adquisiciones, la cual está centrada en la compra y en la venta de empresas más que en la compra de empresas manufactureras en cuanto tales.

\section{El entramado locacional e institucional de las finanzas globales}

Varios de los temas hasta aquí discutidos asumen formas particularmente agudas en la emergente red global de centros financieros. El sistema financiero global ha alcanzado niveles de complejidad tales, que requiere la existencia de una red transfronteriza de centros financieros para dar servicio a las operaciones del capital global. Esta red de centros financieros diferirá crecientemente de versiones anteriores del sistema internacional financiero. En un mundo de sistemas financieros nacionales en gran parte cerrados, cada país duplicaba la mayoría de las funciones nece- sarias para su economía; las colaboraciones entre distintos mercados financieros nacionales a menudo no fueron más que la ejecución de un conjunto dado de operaciones en cada uno de los países involucrados, como en casos de compensación y liquidación. Con pocas excepciones, tales como los mercados offshore y algunos de los más grandes bancos, el sistema internacional consistió en una serie de sistemas domésticos cerrados.

La integración global de los mercados presiona hacia la eliminación de varios sistemas redundantes y hace de la colaboración una materia mucho más compleja, cuyo efecto consiste en aumentar la división del trabajo dentro de la red. Más que cada país con su propio centro para las operaciones globales, la tendencia es a la formación de redes y alianzas estratégicas con un cierto grado de especialización y división de funciones. Esto bien podría transformarse en un sistema con menos centros estratégicos y mayores jerarquías. En este contexto, Londres y Nueva York, con sus enormes concentraciones de recursos y talento, continúan siendo los centros neurálgicos de la red global para las operaciones más complejas y estratégicas del sistema como un todo. Ellas son exportadoras líderes de servicios financieros y forman parte típicamente de cualquier oferta pública internacional de importancia, ya sea la privatización de British Telecom o France Telecom. La formación de la Eurozone está fortaleciendo la posición de Francfort y París, cada una de las cuales está siendo parte de intrincadas alianzas entre los centros europeos más relevantes.

Los centros financieros de muchos países alrededor del mundo están cumpliendo de manera creciente funciones de entrada para la circulación interna y externa de capital nacional o extranjero. La incorporación de un número cada vez mayor de estos centros financieros es una forma a través de la cual el sistema financiero global se expande: cada uno de estos centros es el nexo entre la riqueza del país y el mercado global, y entre los inversionistas extranjeros y las oportunidades 
de inversión del país. De esta manera, crece en número el total tanto de las fuentes como de los destinos de la inversión. Las funciones de entrada serán su principal mecanismo para integrarse al mercado financiero global, antes que la producción de innovaciones para el control del flujo de capitales hacia dentro y hacia fuera. El complejo de operaciones tiende a ser ejecutado por empresas de servicios de inversión, contables y legales de nivel superior a través de filiales, sucursales, importaciones directas de estos servicios y algunas otras formas de transferencia.

Estas puertas de acceso al mercado global lo son también para las dinámicas de las crisis financieras: el capital puede fluir hacia fuera tan fácil y rápidamente como hacia adentro. $Y$ aquello que fuera una vez considerado como capital "nacional" puede fácilmente unirse al éxodo ahora: por ejemplo, sabemos ahora que durante la crisis de México de diciembre de 1994, los primeros capitales en huir de los mercados mexicanos fueron nacionales, no extranjeros; y que en la salida de Brasil de un monto estimado de billón de dólares diario a comienzos del otoño de 1999, y que alcanzó sobre cuarenta billones de dólares, no todo era extranjero.

En mi lectura, el sistema financiero globalmente integrado no trata sólo de la competencia entre países. La tendencia es hacia un aumento de esfuerzos colaborativos especializados entre estos centros. Más aún, mientras los mercados se integran, el crecimiento en su conjunto se maximiza con el crecimiento en todos los centros. La crisis en Tokio u Hong Kong no crea ventajas para otros centros, excepto tal vez en algunos segmentos muy particulares del mercado. El notorio crecimiento de Londres, Nueva York, París o Francfort es en parte una función de una red global de centros financieros. Desde sus comienzos, Hong Kong ha sido una intersección crucial de diferentes mundos, un nodo de intercambio estratégico para las empresas desde China hacia el resto del mundo y desde el resto del mundo hacia China, así como entre todas las comunidades chinas de ultramar (Meyer, 2002). Pocos centros pueden imitar esta ventaja, pero ellos pueden beneficiarse del rol especializado de Hong $\mathrm{Kong}^{13}$. Hoy en día, aun después de una severa crisis, Hong Kong todavía tiene la más sofisticada concentración de servicios avanzados, después de Londres y Nueva York. Un argumento paralelo puede aplicarse a Tokio: aun cuando su economía esté en crisis, continuará siendo una pieza del sistema financiero global, dada su enorme concentración de recursos financieros ${ }^{14}$.

El rápido crecimiento de las redes electrónicas y mercados introduce una interrogante acerca de la importancia actual de los centros financieros ${ }^{15}$. Siempre que estos últimos combinen los múltiples recursos y talentos necesarios para ejecutar las complejas operaciones y servicios a las empresas globales y los mercados ${ }^{16}$, los centros financieros no pueden ser reducidos a sus intercambios. Ellos son

13 Su ventaja histórica como nexo entre el mundo y China y su concentración de servicios especializados actualizados aseguran un rol estratégico para Hong Kong. El impresionante "Hong Kong as a global metropolis: social networks of capital" de David Meyer es una de la mejores explicaciones de esta peculiar ventaja que posee Hong Kong como intermediario para las redes globales de capital.

14 Por ejemplo, Japón tiene un trillón de dólares en recursos bajo administración institucional, pero otros diez trillones en ahorros y cuentas similares que están por ser desreguladas.

15 El comercio electrónico también contribuirá con un patrón radicalmente nuevo, por el cual un mercado, por ejemplo Frankfurt's Deutsche Eurex, puede operar en pantallas en muchos otros mercados alrededor del mundo, o por el cual una empresa de corredores, Cantor Fitzgerald, puede tener sus precios de Tesorería futuros listados en pantallas utilizadas por comerciantes en todo Estados Unidos (como en septiembre de 1998).

16 Por ejemplo, el énfasis típico en los mercados electrónicos futuros en Francfort vela el hecho de que esta red de futuros electrónicos está en realidad integrada en una red de centros financieros. Y la empresa de corredores Cantor Fiztgerald, que ha computarizado la venta de futuros de Tesorería de Estados Unidos, tiene de hecho una alianza con la Board of Trade de Nueva York para manejar estas ventas. 
parte de una arquitectura mucho más compleja y constituyen estructuras a su vez mucho más complejas dentro de esa misma arquitectura. La tendencia es hacia la intensificación de las redes que conectan los centros financieros en alianzas estratégicas o funcionales. Tales alianzas pueden evolucionar hacia el equivalente de las fusiones y adquisiciones transfronterizas de firmas (Sassen, 2002: capítulos 4, 5 y 7).

¿Cuan lejos pueden llegar las nuevas tecnologías de la comunicación en la eliminación de la necesidad de verdaderos centros financieros y su red, dada especialmente la naturaleza crecientemente electrónica y global del mercado de capitales?

\section{En la era digital: ¿más concentración que dispersión?}

Lo que realmente destaca en la evidencia acerca de la industria financiera global es el grado hasta el cual existe una marcada concentración de las acciones de muchos mercados financieros en unos pocos centros financieros $^{17}$. Londres, Nueva York, Tokio (a pesar de una recesión económica), París, Francfort y algunas otras ciudades aparecen regularmente en los puestos más altos y representan una gran proporción de las transacciones globales. Londres, seguido de Tokio, Nueva York, Hong Kong y Francfort, posee una parte importante de toda la banca internacional. Londres, Francfort y Nueva York tienen una enorme participación en la exportación de servi-

17 Entre las fuentes principales de datos para las cifras citadas en esta sección están el Internacional Bank for Settlements (Basilea); datos de las cuentas nacionales del Fondo Monetario Internacional; publicaciones especializadas de comercio tales como Wall Street Journal's Worldscope, Morgan Stanley Capital Internacional; The Banker; listas de datos de Financial Times y The Economist; y especialmente para las ciudades, los datos producidos por Technimetrics, Inc. Nombres adicionales de estándares y fuentes continuamente actualizadas aparecen en Sassen (2001). cios financieros. Londres, Nueva York y Tokio daban cuenta de un tercio de los holdings institucionales globales de valores a fines de 1997, después de un declive del $32 \%$ en los valores de Tokio durante 1996. Londres, Nueva York y Tokio representan el 58\% del mercado de divisas, uno de los pocos mercados verdaderamente globales; junto con Singapur, Hong Kong, Zurich, Ginebra, Francfort y $\mathrm{Pa}$ rís, representan el $85 \%$ en éste, el más global de los mercados.

Esta tendencia hacia la consolidación en unos pocos centros aún mientras la red de centros financieros integrado se expande globalmente, es también evidente dentro de los países. En Estados Unidos, por ejemplo, Nueva York concentra todos los bancos de inversión líderes, con solamente otro centro financiero internacional de primera importancia en este enorme país, Chicago. Sydney y Toronto han ganado poder igualmente en países de tamaño continental, tomando funciones y cuotas de mercado de aquellos que alguna vez fueron los mayores centros comerciales, Melbourne y Montreal, respectivamente. También lo han hecho Sao Paulo y Bombay, que ganaron participación y funciones a Río de Janeiro en Brasil, y a Nueva Delhi y Calcuta en India, respectivamente. Estos son todos enormes países, y se puede haber pensado que podrían sostener múltiples centros financieros importantes. En Francia, París hoy concentra porciones más grandes de más sectores financieros que hace diez años, y mercados como Lyon, que alguna vez fueron importantes mercados de valores, se han transformado en "provinciales", aunque Lyon actualmente es el centro de una pujante región económica. Milán privatizó su intercambio en septiembre de 1997, y fusionó electrónicamente los diez mercados regionales de Italia. Francfort concentra ahora una parte mayor del mercado financiero en Alemania que a comienzos de los ochenta y así también lo hace Zurich, que una vez tuvo a Basilea y Ginebra como competidores significativos. Este patrón es evidente en muchos países. Más aún, la tendencia hacia la consolidación de un centro fi- 
nanciero líder en cada país es una función de rápido crecimiento en el sector no de la declinación de las ciudades perdedoras.

Hay al mismo tiempo consolidación en menos centros principales a través y dentro de los países y un marcado crecimiento en el número de centros que se transforman en parte de la red global, a medida que los países respectivos desregulan sus economías. Sao Paulo y Bombay, por ejemplo, se unieron a la red financiera global después que Brasil e India desregularan (parcialmente) sus sistemas financieros. Este modo de incorporación a la red global tiene a menudo el costo de la pérdida de funciones respecto de cuando eran grandes centros nacionales. Hoy en día las empresas líderes financieras, contables y de servicios legales, usualmente extranjeras, penetran en sus mercados para manejar las nuevas operaciones transfronterizas. Esta incorporación habitualmente sucede sin una ganancia en la parte del mercado global que ellas pueden dominar, aun cuando su capitalización pueda aumentar, a menudo de manera significativa, y aún cuando ellas sumen al volumen total en el mercado global.

¿Por qué en tiempo de rápido crecimiento en la red de centros financieros, en los volúmenes totales y las redes electrónicas tenemos tan alta concentración de porciones del mercado en los centros líderes, globales y nacionales? Tanto la globalización como el intercambio electrónico tratan de la expansión y de la dispersión, más allá de lo que había sido el confinado ámbito de las economías nacionales y las operaciones de piso. En realidad, uno bien podría preguntarse por qué, después de todo, los centros financieros importan.

\section{8. ¿Por qué la necesidad de centros en la era digital global?}

La importancia continua de los centros principales es, de alguna manera, un contrasentido, como lo es -a este respecto- la existencia de una vasta red de centros financieros. El rápido desarrollo de los intercambios electrónicos, la digitalización creciente de buena parte de la actividad financiera, el hecho que las finanzas hayan llegado a ser uno de los sectores líderes en un número cada vez mayor de países, siendo que producen un producto desmaterializado e hipermóvil, todo ello sugiere que la localización no debería importar. De hecho, la dispersión geográfica parecería ser una buena alternativa dado el alto costo de operación en los centros financieros principales. Aún más, en los últimos diez años se ha visto una movilidad geográfica acrecentada de expertos financieros y empresas de servicios financieros.

Hay, en mi opinión, por lo menos tres razones que explican la tendencia hacia la consolidación en algunos pocos centros más que una dispersión masiva ${ }^{18}$.

\subsection{La importancia de la conectividad social y de las funciones centrales}

Primero, mientras las nuevas tecnologías de la comunicación realmente facilitan la dispersión geográfica de las actividades económicas sin perder la integración del sistema, han tenido también el efecto de reforzar la importancia de la coordinación central y las funciones de control de las empresas, y aún de los mercados. En realidad, para las empresas de cualquier sector, el operar una red de sucursales y filiales ampliamente dispersa y en múltiples mercados han hecho que las funciones centrales sean mucho más complicadas. Su ejecución requiere acceso a habilidades superiores no sólo dentro de las sedes de gestión, sino también -más generalmente- a me-

18 Ya desarrollé este análisis en la primera edición de The Global City, centrándome en Nueva York, Londres y Tokio. Desde entonces, los hechos han aparecido más claros y pronunciados que como los elaboré en la segunda edición. Varios de los capítulos en Global Networks, Linked Cities también nos proveen de especificaciones empíricas detalladas de algunas de estas tendencias. 
dios innovadores en tecnología, contabilidad, servicios legales, predicción económica y toda clase de servicios especializados, muchos de los cuales son nuevos. Los centros más importantes tienen concentraciones masivas de recursos que les permiten maximizar los beneficios de las nuevas tecnologías de la comunicación y gobernar las nuevas condiciones para operar globalmente. Hasta los mercados electrónicos como NASDAQ y E*Trade confían en comerciantes y bancos que están localizados en otra parte, al menos algunos de ellos en un centro financiero de importancia.

Un hecho que se ha vuelto cada vez más evidente es que al maximizar los beneficios de las nuevas tecnología de la información, las empresas no sólo necesitan de infraestructura, sino de una compleja mezcla de otros recursos. La mayor parte del valor agregado que estas tecnologías pueden producir para empresas de servicios avanzados radica en las así llamadas externalidades. Y esto significa el material y los recursos humanos -modernos edificios de oficinas, habilidades superiores y la infraestructura de red social que maximiza la conectividad. Cualquier ciudad puede tener cables de fibra óptica, pero esto no es suficiente (García, 2002).

Un segundo hecho que está emergiendo con mayor claridad se refiere al significado de "información". Hay dos tipos de información (Sassen, 2001: capítulo 5). Uno es el dato, que puede ser complejo pero que sin embargo es de conocimiento general: el nivel al cual cierra un mercado de valores, la privatización de una empresa pública, la quiebra de un banco. Pero hay un tipo mucho más difícil de "información", relacionado con la evaluación, interpretación y juicio. Esto implica negociar una serie de datos e interpretaciones de una mezcla de datos, con la esperanza de producir datos de orden superior. El acceso al primer tipo de información es ahora global e inmediato desde cualquier lugar del mundo más desarrollado, gracias a la revolución digital. Pero hay un segundo tipo de información que requiere una mezcla complicada de elementos -la infraestructura social para la conectividad global- que otorga a los centros financieros mayores una dimensión de liderazgo.

Es posible, en principio, reproducir la infraestructura técnica en cualquier lugar. Singapur, por ejemplo, posee una conectividad técnica que se equipara a la de Hong Kong. Pero, ¿tiene Hong Kong conectividad social? Podríamos decir lo mismo de Francfort y Londres. Cuando las formas más complejas de información necesarias para ejecutar contratos internacionales mayores no se pueden obtener de las bases de datos existentes, sin importar cuánto se pueda pagar, se necesita entonces el circuito de la información social y las interpretaciones e inferencias de facto asociadas que rebotan de la información entre la gente habilidosa e informada. Es la importancia de este insumo lo que ha dado una nueva preeminencia a las agencias de calificación de crédito, por ejemplo. Parte de esta calificación tiene que ver con la interpretación y con la inferencia. Cuando esta interpretación se hace "fidedigna", se transforma en "información" disponible para todos. El proceso de transformar inferencias e interpretaciones en "información" requiere de una mezcla de habilidades y de recursos.

En resumen, los centros financieros proveen a la conectividad social que le permite a una empresa o mercado maximizar los beneficios de su conectividad tecnológica.

\subsection{Fusiones y alianzas transfronterizas}

Los participantes globales de la industria financiera necesitan enormes recursos, tendencia que está llevando a rápidas fusiones y adquisiciones de empresas y a alianzas estratégicas entre los mercados en diferentes países. Esto está sucediendo en una escala y en combinaciones que pocos habrían previsto tan sólo tres o cuatro años atrás. Hay un número creciente de fusiones entre respectivas empresas de servicios financieros, contables, legales, de seguros, en resumen, empresas que 
necesitan proveer un servicio global. Una evolución similar es también posible para la industria global de las telecomunicaciones, que tendrá que consolidarse para ofrecer un servicio de cobertura global actualizado a sus clientes globales, entre los cuales están las empresas financieras.

Argumentaría que aún otro tipo de fusión es la consolidación de redes electrónicas que conectan un número muy selecto de mercados. En Europa, más de 30 bolsas de valores han estado considerando varias alianzas. Euronetx (NEXT) es la fusión más grande de bolsas de Europa, una alianza entre París, Ámsterdam y Bruselas. También están emergiendo pequeñas bolsas: en marzo de 2001 Tallin Stock Exchange -en Estonia- y su contraparte en Helsinki crearon una alianza. Un patrón nuevo son las adquisiciones hostiles no de empresas sino de mercados, como el intento por parte de los propietarios de la bolsa de Estocolmo de comprar la de Londres (por un precio de 3,7 billones de dólares). Existen varias redes perdedoras que conectan con los mercados que han sido abiertos en los últimos años. En 1999, NASDAQ, el segundo mercado de valores más grande después del New York Stock Exchange (NYSE), abrió Nasdaq-Japón, y en 2002, Nasdaq-Canadá. Esto da a los inversionistas en Japón y Canadá acceso directo al mercado en Estados Unidos. Toronto Stock Exchange ha establecido una alianza con NYSE para crear una plataforma de comercio global separada. NYSE es miembro fundador de una alianza de comercio global, Global Equity Market (GEM), que incluye diez bolsas, Tokio y NEXT entre ellas. Es probable que estos desarrollos refuercen la red mundial de 30 ó 40 ciudades a través de las cuales las industrias financieras globales operan.

Estos desarrollos bien podrían asegurar la consolidación de un estrato de centros financieros selectos en la cúspide de la red mundial de 30 ó 40 ciudades, a través de la cual opera la industria financiera global. Ahora sabemos también que un centro financiero im- portante necesita tener una parte significativa de las operaciones globales para ser tal. Si Tokio no logra conseguir más operaciones de este tipo, va a perder posiciones en la jerarquía global, no obstante su importancia como exportador de capital. Es esta misma capacidad para las operaciones globales lo que mantendrá a Nueva York en los niveles más altos de la jerarquía, aún cuando es alimentado en buena parte por los recursos y la demanda de inversionistas domésticos. Tomando como indicador las acciones bajo administración, se muestra un patrón similar de dispersión y simultánea concentración en la cima de la jerarquía. La distribución mundial de acciones bajo administración institucional se extiende entre un gran número de ciudades que se han integrado durante los últimos años al mercado global de acciones, con desregulación de sus economías y la noción de "mercados emergentes" como un atractivo destino de inversión. En 1999, los administradores institucionales de dinero controlaron aproximadamente 14 trillones de dólares. Thomson Financials, por ejemplo, ha estimado que a fines de 1999, 25 ciudades dieron cuenta del $80 \%$ de la tasación mundial. Estas 25 ciudades dieron cuenta además de aproximadamente el $48 \%$ de la capitalización del mercado total mundial, que se mantenía a 24 trillones de dólares a fines de 1999. Por otra parte, este mercado global se caracteriza por una concentración desproporcionada en las 6 ó 7 ciudades de más alto nivel. Londres, Nueva York y Tokio reunidas dieron cuenta de un tercio de las acciones totales mundiales bajo administración institucional en 1999.

Estos desarrollos dejan en claro una segunda importante tendencia, que en muchos sentidos caracteriza la era global actual. Estos varios centros no simplemente compiten entre sí: hay colaboración y división del trabajo. En el sistema internacional de la década de la posguerra, el centro financiero de cada país cubría en principio el universo de las funciones necesarias para servir a las compañías y mercados nacionales. El mundo de las finanzas era, por supuesto, mucho más simple 
que hoy en día. En las etapas iniciales de la desregulación, en los ochenta, había una fuerte tendencia a observar la relación entre los centros principales como una competencia directa entre Nueva York, Londres y Tokio, entonces como ahora los centros más importantes en el sistema. Pero en mi investigación sobre estos tres centros encontré una clara evidencia de la división del trabajo ya en los ochenta. Lo que estamos viendo ahora es un patrón adicional, según el cual la cooperación o división de las funciones está de algún modo institucionalizada: alianzas estratégicas no sólo entre empresas a través de las fronteras, sino también entre mercados. Hay competencia, colaboración estratégica y jerarquías ${ }^{19}$.

La tendencia hacia las jerarquías en la red global es susceptible de ser reforzada por la reciente formación de la unión monetaria de Europa: la eliminación de varias funciones financieras, principalmente el comercio de divisas, ha alimentado la existencia de un centro financiero "internacional" en cada país miembro, la consolidación de los mercados de bonos gubernamentales, un mercado con una sola moneda con una tasa de interés de corto plazo y una fuerte tendencia hacia un mercado de valores fundamentalmente único.

En resumen, la necesidad de enormes recursos para manejar operaciones crecientemente globales, en combinación con el crecimiento de funciones centrales - descritas anteriormente- produce fuertes tendencias hacia la concentración, y por lo tanto, hacia la jerarquía en una red en expansión ${ }^{20}$.

19 Para un desarrollo más completo de todos estos temas, ver Sassen (2001).

20 Por ejemplo, la globalización de la banca de inversión y la administración de fondos, dos áreas donde las empresas de Nueva York tienen un rol fundamental, pueden haber sido más importantes en reforzar la posición de Londres como centro financiero, que el crecimiento nacional per se del Reino Unido. En The Global City afirmé que la globalización de mercados reduce la importancia de la salud económica nacional, para que las ciudades más relevantes

\subsection{Elites y proyectos desnacionalizados}

Tercero, el rol de lo nacional se está debilitando para estas empresas globales -incluso empresas nacionales con operaciones mundiales- y sus clientes. Así, los principales bancos de inversión de Estados Unidos y Europa han abierto oficinas especializadas en Londres para manejar varios aspectos de sus negocios globales. Hasta los bancos franceses han abierto algunas de sus operaciones especializadas en Londres, algo inconcebible incluso hace pocos años y que aún no es admitido en la retórica nacional.

La desregulación y privatización han debilitado aún más la necesidad de centros financieros nacionales. El asunto de la nacionalidad simplemente funciona de manera diferente en estos sectores respecto de como lo hacía incluso una década atrás. Los productos financieros globales son accesibles en los mercados nacionales, y los inversionistas nacionales pueden operar en los mercados globales ${ }^{21}$. Por ejemplo, algunas de las principales empresas brasileñas aparecen hoy en la bolsa de Nueva York sin pasar por la de Sao Paulo, una nueva práctica que ha causado conmoción en los círculos especializados en Brasil.

Se puede describir este proceso como una incipiente desnacionalización de ciertas arenas institucionales. Puede argumentarse que tal desnacionalización es una condición necesaria para la globalización económica como la conocemos hoy. La sofisticación de este sis-

\footnotetext{
prosperen como centros de negocios internacionales -no necesariamente un rasgo deseable del sistema económico global. Esto parece estar sucediendo en varios países europeos, donde la prosperidad de los mercados de valores va a la par con un desarrollo económico lento y alto desempleo. En particular Schiffer (2002) encuentra un patrón similar en Sao Paulo.

21 Por ejemplo, los bancos de inversión solían dividir sus grupos de análisis por países, para cubrir un mercado nacional; ahora es más probable que lo hagan por sectores industriales (ver, por ejemplo, "Latin American Finance", varios números).
} 
tema subyace en el hecho de que sólo necesita involucrar áreas institucionales estratégicas - la mayoría de los sistemas nacionales pueden ser dejados básicamente inalterados. China es un buen ejemplo. Adoptó reglas de contabilidad internacionales en 1993, necesarias para tomar parte en transacciones internacionales. Para lograrlo, no tuvo que cambiar mucho su economía doméstica. Las empresas japonesas que operaban en ultramar adoptaron tales estándares mucho antes que el gobierno japonés pensara en requerirlos. En este sentido, el aspecto "absoluto" de la globalización es bastante distinto a los mercados globales de consumidores, en los cuales el éxito requiere de la alteración de las preferencias nacionales a nivel masivo. Este proceso de desnacionalización ha sido reforzado por una política estatal que permite la privatización y las adquisiciones extranjeras. En cierto modo, podría decirse que la crisis financiera asiática ha funcionado como un mecanismo para desnacionalizar, al menos en parte, el control sobre aspectos claves de las economías, las cuales -mientras permitían la entrada masiva de inversión extranjera- nunca renunciaron a tal control (Olds et al., 1999)22.

22 Por ejemplo, Lehman Brothers compró las hipotecas residenciales de Thai, de un valor de medio billón de dólares, con un $53 \%$ de descuento. Este fue el primer remate conducido por la Financial Restructuring Authority del gobierno de Thai, que está manejando la venta de 21 billones de dólares de recursos de las compañías financieras. También adquirió las operaciones de Thai de Peregrine, el banco de inversión de Hong Kong que fracasó. La caída en los precios y en el valor del yen ha hecho que las empresas y propiedades japonesas sean blancos atractivos para los inversionistas extranjeros. Merryl Lynch ha comprado 30 sucursales de Yamaichi Securities; Societé Générale Group está comprando el $80 \%$ de Yamaichi Internacional Capital Managment; Travellers Group es ahora el más grande accionista de Nikko, el tercer corredor más grande; y Toho Mutual Insurance Co. anunció una joint venture con GE Capital. Estos son sólo algunos de los ejemplos más conocidos. Mucha de la valiosa propiedad en Ginza -el distrito comercial y de negocios más valorado de Tokio- está siendo considerado ahora para su adquisición por parte de inversionistas extranjeros, en respuesta a la adquisición del Rockefeller Center por parte de Mitsubishi una década atrás.
Los principales centros de negocios internacionales producen lo que podríamos considerar una nueva subcultura, un movimiento desde la versión "nacional" de las actividades internacionales hacia una versión "global". La larga resistencia en Europa a las fusiones y adquisiciones, especialmente a las adquisiciones hostiles o a la propiedad y control extranjeros en Asia del Este, señala a las culturas de negocios nacionales que de alguna manera son incompatibles con la nueva cultura económica global. Diría que las ciudades más importantes y la variedad de las denominadas reuniones de negocios globales (tales como el Foro Económico Mundial en Davos y otras ocasiones similares), contribuyen a desnacionalizar las elites corporativas. Si esto es bueno o malo, es un asunto aparte, pero argumentaría que es una de las condiciones para asentar a los sistemas y subculturas necesarias para un sistema económico global.

\section{En conclusión}

La globalización económica y las telecomunicaciones han contribuido a producir una espacialidad para lo urbano, que depende tanto de redes transfronterizas como de localizaciones territoriales con concentraciones masivas de recursos. Esta no es una característica completamente nueva. Por siglos, las ciudades se han encontrado en la intersección de procesos mundiales a menudo mayores. Lo que es hoy diferente es la intensidad, la complejidad y la escala global de estas redes; el grado hasta el cual buena parte de las economías hoy se van desmaterializando a través de la digitalización y -por lo tanto- el grado hasta el cual ellas pueden circular a grandes velocidades a través de algunas de estas redes; y en tercer lugar, el creciente número de ciudades que son parte de redes transfronterizas que operan a escalas geográficas vastas. También es diferente hoy el desarrollo de regímenes regulatorios transfronterizos y la participación de los estados nacionales en la producción de los instrumentos legales y técnicos necesarios para la inserción en el sistema económico global. 
El crecimiento de las transacciones altamente especializadas que conectan a las ciudades está generando una diversidad en los tipos de redes interurbanas. Aquí podemos incluir, entre otras, las redes globales de filiales de empresas; la particular arquitectura de conectividad que emerge de los intereses de aquellos actores que tienen el poder de promover su desarrollo; la formación de jerarquías regionales transfronterizas facilitada por las zonas de libre comercio y los corredores internacionales de crecimiento; y la integración de un número creciente de centros financieros al mercado global de capitales.

La integración a estas redes de transacciones altamente especializadas ha requerido a menudo masivas transformaciones en partes cada vez mayores de estas ciudades, así como importantes cambios políticos por parte de los estados involucrados. El desarrollo de las funciones de la ciudad global está ligado al desarrollo de infraestructura física y política, lo que redunda en un nuevo orden político, económico y espacial en tales ciudades, al mismo tiempo que dinámicas de origen más antiguo también siguen vigentes. La profundidad de estas transformaciones puede en parte subsumirse -en algunas de estas ciudadesbajo el síndrome de la megaciudad y de las correspondientes dinámicas sociales, económicas y espaciales que caracterizan las grandes ciudades. La nueva espacialidad urbana producida al transformarse las ciudades en lugares de transacciones transfronterizas es, por lo tanto, parcial en un doble sentido: da cuenta de sólo parte de lo que sucede en las ciudades y de lo que éstas son; y habita sólo parte de lo que podríamos considerar como el espacio de la ciudad. Se producen entonces nuevas articulaciones con los circuitos globales y desarticulaciones dentro de la ciudad.

\section{Referencias bibliográficas}

Abbot, C. (1996). "The internationalization of Washington, D.C." Urban Affaire Review, 31, 5: 571-594.
Abu-Lughod, J. L. (1999). New York, Los Angeles, Chicago: America's global cities. Minnesota: University of Minnesota Press.

Allen, J., D. Massey y M. Pryke (eds.) (1999). Unsettling cities. London: Routledge.

Castells, M. (1996). The networked society. Oxford: Blackwell.

Ciccolella, P. \& I. Mignaqui (2002). "The spatial reorganization of Buenos Aires". Sassen, S. (ed.), Global networks/linked cities. New York/London: Routledge.

Cochrane, A., J. Peck y A. Tickell (1996). "Manchester plays games: exploring the local politics of globalization". Urban Studies, 33, 8: 1319-1336.

Cohen, S. S. \& J. Zysman (1987). Manufacturing Matters: The Myth of the Post-Industrial Economy. New York: Basic Books.

Daniels, P. W. (1991). "Producer services and the development of the space economy". Daniel, P. W. \& F. Moulaert (eds.), The changing geography of advanced producer services. London/New York: Belhaven Press.

Drennan, M. P., E. Tobier y J. Lewis (1996). "The interruption of income convergence and income growth in large cities in the 1980s". Urban Studies, 33, 1:63-82.

García, L. (2002). "The architecture of global networking technologies". Sassen, S. (ed.), Global networks/linked cities. New York/ London: Routledge.

Graham, S. (2002). "Splintering urbanism". Sassen, S. (ed.), Global networks/linked cities. New York/London: Routledge.

Graham, S. \& S. Marvin (2001). Splintering urbanism. Networked infrastructures, technological mobilities and the urban condition. New York/London: Routledge.

King, A. D. (ed.) (1995). Representing the city: ethnicity, capital and culture in the 21st Century. London: Macmillan.

Landrieu, J., N. May, D. Par, T. Spector y P. Veltz (eds.) (1998). La ville éclatée. La Tour d'Aigues: Ediciones de l' Aube.

Lo, F. \& Y. Yeung (eds.) (1996). Emerging world cities in Pacific Asia. Tokyo: United Nations University. 
Markusen, A. \& V. Gwiasdam (1994). "Multipolarity and the layering of functions in the world cities: New York City's struggle to stay on top". Internacional Journal of Urban and Regional Research, 18: 167193.

Mitchell, W. J. (1996). City of bits: space, pla$c e$, and the Infobahn. Cambridge, MA: The MIT

Press. Noyelle, T \& A. B. Dutka (1988). Internacional trade in business services: accounting, advertising, law and management consulting. Cambridge, MA.: Ballinger Publishing.

Olds, K., P. Dicken, P. F. Kelly, L. Kong y H. W. Yeung (eds.) (1999). Globalization and the Asian Pacific: contested territories. London: Routledge.

Parnreiter, C. (2002). "Mexico: the making of a global city”. Sassen, S. (ed.), Global networks/linked cities. New York/London: Routledge.

Parsa, A. \& R. Keivani (2002). "The Hormuz Straights: towards a cross-border growth corridor". Sassen, S. (ed.), Global networks/ linked cities. New York/London: Routledge. Santos, M., M. A. A. de Souze y M. L. Silveira (eds.) (1994). Territorio globalizaçao e fragmentaçao. Sao Paulo: Editorial Hucitec.

Sassen, S. (2001). The global city: New York, London; Tokyo. Princeton: Princeton University Press.

(ed.) (2002). Global networks/ linked cities. New York/Londres: Routledge.

Schiffer, S. (2002). "Sao Paulo: articulating a cross-border regional economy". Sassen, S. (ed.), Global networks/linked cities. New York/London: Routledge.

Veltz, P. (1996). Mondialisation, villes et territoires. Paris: Presses Universitaires de France. 